\title{
Blended Learning Using Lms-Moodle with Cloud Computing to Enhance Analytical Thinking for Undergraduate Students
}

\author{
Naruenart Khunnatham ${ }^{1+}$, Tawee Sranamkam ${ }^{2+}$ and Rachadaporn Benchawattananon ${ }^{3+}$ \\ ${ }^{1}$ narukh@kku.ac.th, Educational Technology, Khon Kaen University. Thailand \\ ${ }^{2}$ tawsra@kku.ac.th, Educational Technology, Khon Kaen University. Thailand \\ ${ }^{3}$ rachadaporn@kku.ac.th, Forensic Science, Khon Kaen University. Thailand
}

\begin{abstract}
The purposes of this research were to 1) create blended learning using LMS - Moodle with on cloud computing to enhance analytical thinking for undergraduate students 2) study the analytical thinking This research was a quasi- experimental, the samples were 108 students, were selected by simple random sampling. The instrument used in this research were blended learning using LMS - Moodle with cloud computing to enhance analytical thinking for undergraduate students, lesson plan, analytical thin king test, learning achievement test. The results showed that the Efficiencies of blended learning using LMS - Moodle were 90.06/85.60. The post-test analytical Thinking scores of Students were higher than the pre-test score. Statistically significant at the .05 level.
\end{abstract}

Keywords: Blended Learning, Analytical thinking, Cloud Computing, Moodle, Undergraduate

\section{Introduction}

The current study is progressing steadily. The process and channels of learning or self-study of learners, more favorable than in the past. Due to the development of technology and communication, it has become a wireless education. In addition, linked together as a network to the world. Learners can self-study anytime, anywhere with an internet connection. Moreover, there is an interaction with the environment. The process is organized. Diverse teaching to provide effective learning management. In addition, create interesting to the students. The tool can use. [1] Blended Learning it is another form of learning that merges online and traditional learning in a classroom. The students learn self-learning. Cloud Computing is a way to share information. Online learning can create interactive multimedia, collaborative activities that enhance learning together when applied to the integrated learning, which can use to regrade as a learning tool. [2]. Analytical ability is one of the important skills to promote in teaching and learning. Because of analytical thinking can develop and apply that occur in everyday life or seen is something that helps to strengthen the power of thinking to solve problems using life experiences. Therefore, it is necessary to measure that How much is the potential of the learner. [3]

For these reasons, researchers focused on promoting analytical thinking. By creating an integrated blended learning with LMS - Moodle to enhance analytical thinking for undergraduate students, Khon Kaen University, Thailand.

\section{Objectives}

2.1 To create efficiency blended learning using LMS - Moodle with on cloud computing to enhance analytical thinking for undergraduate students

\subsection{To compare the analytical results of the students who learned by blended learning.}

\section{Research hypothesis}

\footnotetext{
+ Corresponding author.

E-mail address: narukh@kku.ac.th ${ }^{1}$, tawsra@gmail.com ${ }^{2}$, rachadaporn@kku.ac.th ${ }^{3}$
} 
3.1 Blended learning using LMS - Moodle with on cloud computing to enhance analytical thinking for undergraduate students with efficiency according to criteria $85 / 85$.

\subsection{Analytical Thinking of Students Learning with Blended learning After studying more} than before the study is statistically significant at the .05 level.

\section{Research scope}

The content of this research is 300304 Principles of Personal Identification. Department of Integrated Science Faculty of Science, Khon kaen University, Thailand.

\section{Methodology}

\subsection{Population}

The population were Khon Kaen University students. Registered in the course 300304 Principles of personal identification. In special education, the academic year 2017, with a population of 259 people.

\subsection{Sample}

The samples were Khon Kaen University students. Registered in the course 300304 Principles of personal identification. In third semester of academic year 2017, with 108 samples were selected by simple random sampling method

\subsection{Instruments}

5.3.1 Plan of Blended learning of courses 300304 Principles of identification of personal identification, which has a method to create teaching plans as follows

1) Study textbooks related to writing educational plans Study the details of the course (Course Syllabus) from the instructor. In addition, study the course content to divide the content of each week or hours of teaching

2) Study the contents of the course to be consistent and suitable for both traditional and online teaching and learning.

5.3.2 Blended learning using LMS - Moodle with on cloud computing to enhance analytical thinking for undergraduate students how to create blended learning the following:

1) Study and analyze research related to teaching and learning on Moodk, both from textbooks and research, as well as analyzing data of course content, pre-school and post-test activities used on Moodle.

2) Study various software information Used to create tutorials on Moodle.

3) Study and analyze basic information in teaching and learning Define learning content Define behavioral objectives.

4) Install the information of the program used to create blended lessons. And designing the web page layout, defining the webpage components before the actual design.

5) Blended Learning according to the model of ADDIE Model 5 steps, which consists of With 1. Analysis 2. Design 3. Development 4. Implementation and 5. Evaluation and Revise.

\subsubsection{Analytical Thinking Test}

The pre-study and post-test measures based on four multiple-choice and 20 subjective and 2 open-ends. The methods for creating and evaluating the following tools are as follows.

1) Content analysis and learning objectives Lesson.

2) Defines the general objectives and behavioral objectives. Check accuracy by experts.

3) Create analytical thinking Multiple-choice subjective form, 20 items, Subjective, 2 items, using the basis of the composition of analytical thinking skills of 3 elements: 1) critical thinking, 2) analyzing relationships 3) analyzing the principles

4) Content validity assessed by examining the consistency of each item with the intended purpose. Criteria to consider and improve upon the instructions below: [4]

+1 sure that the questionnaire consistent with the behavioral objectives stated 
0 Not sure questions correspond to the behavioral objectives stated

-1 sure the question is not consistent with the behavioral objectives stated.

The test of the Index of Consistency (IOC) by three experts. If any question is not consistent or the IOC is less than 0.67 , then the question will improve and reviews by experts. Evaluate until it has an index consistency of 0.67 or higher, and then take a test that verified by expert. Then update to test for the difficulty index (p), the discriminative power ( $r$ ) and the confidence (a) of the test.

\subsubsection{Achievement test}

Learning achievement test form before and after learning online is a multiple-choice test of four choices of answers, 30 items. There are methods to create and find the efficiency of the following tools.

1) Content analysis and learning objectives of the lesson then study the content and learning objectives

2) Determine general objectives and behavioral objectives that are consistent with six level of leaming behavior of Bloom Taxonomy, and send it to experts for reviewing the accuracy of the achievement test.

3) Create a multiple-choice achievement test form, four choices of answers, 30 items Using the basic learning behavior level, 6 levels of Bloom Taxonomy are Remembering, Understanding, Applying, Analyzing, Evaluation and Creating. [5]

4) To provide expert examination content validity by considering the following. Looped between each test with behavioral objectives using. Criteria for consideration and to improvement upon the instructions below:

+1 sure that the questionnaire consistent with the behavioral objectives stated

0 Not sure questions correspond to the behavioral objectives stated -1 sure the question is not consistent with the behavioral objectives stated.

The test of the Index of Consistency (IOC) by three experts. If any question is not consistent or the IOC is less than 0.67 , then the question will update and review by the expert. Evaluate until it has an index consistency of 0.67 or higher, and then take a test that verified by an expert. To update and tested with students 30 for the Difficulty Index (p), the discriminative power (r), and the reliability (a) of the test.

\subsection{Data Collection}

In this research. Researchers have collected data. The place to store data is the Faculty of Science. Time to teach 6 times, 3 hours each, collected during June 13, 2018 - July 27, 2018 with the following

\subsubsection{Preparation.}

1) Action Plan and research related.

2) Study of problems in learning in the course 300304 Principles of personal identification

3) Study documents and research related to learning with Blended learning.

4) The period of the study. 1 month 11 days, 13 June - 29 July 2018

5) Prepare the group to use in research. By appointment date and where the teaching

6) To prepare the lessons learned with the Blended Learning. To support self-learning.

7) Detailed pattern of teaching integrated activities instructor acknowledge

\subsubsection{Implementation}

1) The researcher clarifies and recommends learning with integrated lessons. The purpose of the course and blended learning for the students.

2) The students take the test before the class. It is a 20-item multiple-choice questionnaire and the achievement test 30 multiple-choice questions before the regular classroom in the next.

3) Learning and instruction. There are students attend self-directed learning lessons. In addition, do activities online job postings. Students must verify their personal code to access the system.

4) When entering the second lesson of the course in the course. Students will give a mission and divide into a groups. There are 4 subgroups per group. There are 27 subgroups for the treatment project. In this project. Have students use Cloud Computing as a medium for project work. The procedure is as follows:

a) Assign topics to students. There are 5 topics for the project. One topic will be 5 - 6 students. 
b) Make a project basedon the topic assigned. Students must follow the process of doing science projects

\subsubsection{Data collection}

After students Study with Blended learning And Face to face in the classroom. Each time already Allow students to do the test after study, to bring the results of the test to the next data analysis.

\subsection{Data Analysis}

5.5.1 Finding the performance of a create blended learning using LMS - Moodle with on cloud computing to enhance analytical thinking for underg raduate students Finding Blended Learning Efficiency In this research, the efficiency of the Blended Learning was determined by the $E_{1} / E_{2}$ method. [6] The efficiency was determined according to the criterion of $85 / 85$.

\subsubsection{Analytical thinking of blended learning using LMS - Moodle with on cloud computing to} enhance analytical thinking for undergraduate students

In analyzing, the data obtained from this research. Researchers analyzed the results of the analysis. The data analyzed by means of percentage, mean, and standard deviation (SD) from 22 items. Validity of the content and consistency of the (IOC) finding difficulty (p) discrimination (r) and confidence (a) to analyze the difference between the before and after.

\section{Research results}

6.1 Finding the effectiveness of blended learning using LMS - Moodle with on cloud computing to enhance analytical thinking for undergraduate students finding the Effectiveness of a Blended Learning Have taken effective steps for the following experiment

\subsubsection{One-to-one Testing}

Try it out with 4 students with high, one high and one low. From Unit 1, Orientation to Unit, 4 students will do exercises or activities in the after-class lessons for 30 items. The results of the experiment analyzed for E1 / E2 performance. From the experiments, solved as follows:

1) The content of some lessons in Blended Learning is too long, when access through the mobile phone takes time to scroll down. It is difficult to modify the content of the lesson. Moreover, cut some pages with too long content. The move to add another page

2) Visual info graphic that used some colorful flashy look dazzled by adjusting the image editing Info graphics. Have a similar ridge. To comfortably and enhance the beauty

3) Narrate each page there was too light by adjusting the audio louder.

4) Some font size is too small by resizing the text to fit a small or too large.

\subsubsection{Small Group Testing}

Try it out with 12 students with high, low, and low academic achievement. From Unit 1, Orientation to Unit 4, during the lesson, students do exercises or activities in the lesson after the students have to do 30achievement test. Then the results of the experiment. Analysis of E1/ E2 performance.

\subsubsection{Field Group Testing}

Try it out with 92 students who have high, relatively high, low, and low grades. From Unit 1, Orientation toUnit 4, during the lesson, students do exercises or activities in the after-class lessons for the students to do 30 achievement tests. Then, the results of the experiment analyze for efficiency of blended leaming (E1/E2).

Table1: Show the effectiveness of the Blended Learning testing

\begin{tabular}{lccc}
\hline Testing & $\begin{array}{c}\text { Experimental } \\
\text { group. }\end{array}$ & $\begin{array}{c}\text { Number of students } \\
\text { (persons) }\end{array}$ & $\begin{array}{c}\text { Efficiency of the } \\
\text { Blended Learning } \\
\text { (E1 / E2) }\end{array}$ \\
\hline One-to-one Testing & 1 & 4 & $70.83 / 85.83$ \\
\hline Small group Testing & 3 & 12 & $93.30 / 82.20$ \\
\hline Field group Testing & 23 & 92 & $90.06 / 85.60$ \\
\hline
\end{tabular}


Table 1 shows that one-to-one experiments the efficiency was $70.83 / 85.83$. Small group testing efficiency was 93.30 / 82.20 and Field group Testing Get the efficiency of the Blended Learning E1 / E2 equal to 90.06 / 85.60 which is effective according to the criteria set is $85 / 85$.

\subsection{Comparison of the results of the analysis. For undergraduate students before and after} class.

Results of the analys is before and after class. From experiments with samples of 108 people has resulted in Table 2.

Table 2: Comparison the analytical results of the students who learned by blended learning

\begin{tabular}{lccccc}
\hline \multicolumn{1}{c}{ Score } & $\begin{array}{c}\text { Number } \\
\text { of Sample }\end{array}$ & $\begin{array}{c}\text { Max. } \\
\text { Score }\end{array}$ & $\begin{array}{c}\text { Mean } \\
\text { (points) }\end{array}$ & SD. & P \\
\hline $\begin{array}{l}\text { pre-test } \\
\text { scores } \\
\text { post-test } \\
\text { scores }\end{array}$ & 108 & 30 & 13.91 & 3.25 & $0.000^{*}$ \\
\hline$* \mathrm{P}<.05, \mathrm{df}=107$ & 108 & 30 & 20.63 & 4.11 & \\
\hline
\end{tabular}

From the table 2, the pre-test Score of analysis thinking Of 108 students from 30 full scores with an average score of 13.91, a standard deviation of 3.25, and an average post-test score was 20.63. The standard deviation was 4.11 , indicating that the post-test scores were significantly higher than the pre-test critical thinking scores of .05 level.

\section{Conclusion and Discussion}

\subsection{Dis cuss the results of the Blended learning.}

From the experiments to find the efficiency of the Blended Learning, efficiency is $90.06 / 85.60$ because the trial conducted in various stages. To find out after that, we conducted a small group test to find out the performance and correct the defects of the integrated lesson. Field testing and post-graduate achievement scores were statistically significant at .05 .

\subsection{Comparison of analytical thinking scores for undergraduate students during pre-Test and Post-test}

Comparative Analysis Score the students with the Blended Learning. It found that 108 students had an average of 13.90 for the pre-test and the average score for the post-test was 20.63 . The post-test scores were significantly higher than the pre-test scores. At the .05 level, because of the instructional process that encourages the students to apply the skills and analytical process in three aspects, another important Relationships and the core of thinking

\subsection{Comparison of academic achievement scores for undergraduate students between before and after school}

The results of comparison of learning achievement scores of students studying with Blended Learning It was found that 108 students had an average score of 15.43 for the achievement test before learning and had an average score of 25.57 after the learning achievement test. Statistical at the level of .05.

\section{Suggestions}

\subsection{Suggestions for the next research.}

8.1.1 Research should be by changing the target group to the same class. To know that affect the thinking and the student achievement.

8.1.2 There should be comparative research between students learning with traditional teaching and the group that is teaching and learning with blended learning.

\section{Acknowledgements}


I would like to express my deepest and sincere gratitude to Research Publication Scholarship Fiscal Year of 2019, Graduate School, Khon Kaen University, For supporting this research conference.

\section{References}

[1] Clark, G. (1996). Glossary of CBT/WBT terms. (Online). Available: http://www.clark.net/pub/nractive/alt5.htm[9 June 2002]

[2] Doherty, A. (1998). The Internet: Destined to Become a Passive Surfing Technology. Educational Technology. 38(5), September-October 1998:61-63.

[3] D. Randy Garrison \& Norman D. Vaughan. (2008). Blended Learning in Higher Education: Framework, Principles, and Guidelines. San Francisco: Jossey-Bass.

[4] Likert, Rensis A. (1961). New Patterns of Management. New York: McGraw-Hill Book Company Inc.

[5] Anderson, L. W., \& Krathwohl, D. R. (2001). A taxonomy for learning, teaching, and assessing: A revision of Bloom's taxonomy of educational objectives. New York: Addison Wesley Longman.

[6] Chaiyong Bhrommawong. (2002). Educational Administration, Sukhothai Thammathirat Open University. 